\title{
Expression of sugarcane genes induced by inoculation with Gluconacetobacter diazotrophicus and Herbaspirillum rubrisubalbicans
}

\author{
Eduardo de Matos Nogueira ${ }^{1, *}$, Fabiano Vinagre ${ }^{1, *}$, Hana Paula Masuda ${ }^{1, *}$, Claudia Vargas ${ }^{1, *}$, Vânia Lúcia

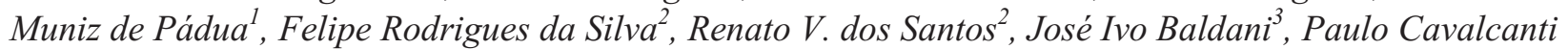 \\ Gomes Ferreiral and Adriana Silva Hemerly,
}

\section{Abstract}

Several Brazilian sugarcane varieties have the ability to grow with little addition of inorganic nitrogen fertilizers, showing high contributions of Biological Nitrogen Fixation (BNF). A particular type of nitrogen-fixing association has been described in this crop, where endophytic diazotrophs such as Gluconacetobacter diazotrophicus and Herbaspirillum spp. colonize plant tissues without causing disease symptoms. In order to gain insight into the role played by the sugarcane in the interaction between this plant and endophytic diazotrophs, we investigated gene expression profiles of sugarcane plants colonized by G. diazotrophicus and H. rubrisubalbicans by searching the sugarcane expressed sequence tag SUCEST Database (http://sucest.lad.ic.unicamp.br/en/). We produced an inventory of sugarcane genes, candidates for exclusive or preferential expression during the nitrogen-fixing association. This data suggests that the host plant might be actively involved in the establishment of the interaction with G. diazotrophicus and $H$. rubrisubalbicans.

\section{INTRODUCTION}

Several Brazilian sugarcane cultivars have the ability to grow with low nitrogen fertilizer inputs. Historically, this crop has been selected in Brazil for high yields with low inputs of inorganic nitrogen fertilizer and, unwittingly, for higher contributions of Biological Nitrogen Fixation (BNF). Endophytic diazotrophic bacteria have been isolated from sugarcane tissues, including Gluconacetobacter diazotrophicus, Herbaspirillum seropedicae and Herbaspirillum rubrisubalbicans. The association of these endophytic diazotrophs with plants has unique features compared with other nitrogen-fixing associations. The bacteria colonize the intercellular spaces and vascular tissues of most organs of the infected plant, without causing visible plant anatomical changes or disease symptoms (Baldani et al., 1997; Reinhold-Hurek and Hurek, 1998). It has been described that the endophytic diazotrophs produce plant growth-regulating hormones, such as auxin (Fuentes-Ramirez et al., 1993) and more recently, gibberellin (Bastian et al., 1998).

It is not yet clear what mechanisms are involved in the establishment of this particular type of interaction, and what kind of molecules mediate signaling between plant and bacteria. In addition, very little is known about the role of the plant in the association. Differences in the contribu- tion of BNF to the plants nitrogen balance in distinct sugarcane cultivars suggest that the plant is controlling, at least in part, the efficiency of the process (Urquiaga et al., 1992). The plant could control bacterial colonization by sending the proper signals and/or providing the best physiological conditions for bacterial survival. Another question to be addressed is how the association benefits the plant. The endophytic diazotrophs promote plant growth when inoculated in sugarcane plantlets (Sevilla et al., 2001), possibly by supplying nitrogen and/or plant hormones.

The investigation of plant gene expression during plant-bacteria associations could be a strategy to unravel the molecular mechanisms of the plant which are involved in this particular type of association between plants and diazotrophic bacteria. Large-scale sequencing of cDNA libraries by the expressed sequence tag (EST) approach has proven to be a powerful tool to discover new genes and to generate gene expression profiles from different cells and tissues grwoing under distinct developmental and physiological conditions (Ohlrogge and Benning, 2000).

In this work presented in this paper, we generated gene expression profiles of sugarcane plants colonized by the endophytic diazotrophs $G$. diazotrophicus and H. rubrisubalbicans in order to get a preliminary view of the plant gene expression during the association. Two sugarcane expressed sequence tag (SUCEST) datasets were examined:

\footnotetext{
*The first four authors (EMN, FV, HPM and CV) contributed equally to the article.

${ }^{1}$ Lab. Biologia Molecular, Depto. Bioquímica Médica, UFRJ, 21941-590 Rio de Janeiro, RJ, Brazil.

${ }^{2}$ CBMEG, UNICAMP, Cx. Postal 6109, 13083-970 Campinas, SP, Brazil.

${ }^{3}$ Embrapa Agrobiologia, BR465 km 47, 23851-970 Seropédica, RJ, Brazil. ${ }^{+}$Send correspondence to A.S.H. E-mail: hemerly@bioqmed.ufrj.br.
} 
(i) selected ESTs that encode proteins that could play a role during the association and (ii) the complete EST set of the cDNA libraries constructed from sugarcane plants inoculated with the diazotrophic endophytes (AD1 and HR1). We identified candidate genes exclusively or preferentially expressed in the AD1 and/or HR1 cDNA libraries, suggesting that sugarcane could be actively involved in the establishment of its association with bacterial endophytic diazotrophs.

\section{MATERIAL AND METHODS}

\section{cDNA libraries}

The studies were performed using the EST Database of the SUCEST (http://sucest.lad.ic.unicamp.br/en/). Of the 37 cDNA libraries that constitute the SUCEST set, 19 libraries that represent distinct tissues/organs of sugarcane plants growing in normal physiological conditions and 2 that represent infected plants were used in our analysis. cDNA libraries with less than 5000 ESTs or normalized were excluded of the analysis. The list of the cDNA library codes is: AD1, AM1, AM2, FL1, FL3, FL4, FL5, HR1, LB1, LB2, LR1, RT1, RT2, RT3, RZ2, RZ3, SB1, SD1, $\mathrm{SD} 2, \mathrm{ST} 1$ and ST3. The number of reads sequenced in each cDNA library and the tissue/organ that it represents is described elsewhere. The AD1 and HR1 cDNA libraries were constructed with mRNA prepared from tissues of the root-stem transition region of in vitro grown plantlets, harvested seven days after inoculation with G. diazotrophicus strain PAL5 (AD1) or H. rubrisubalbicans strain HCC103 (HR1).

\section{Data analysis}

The SUCEST Database consisting of 81.223 clusters (old fragment analysis program (Phrap)) was searched using the key word or basic local alignment search tool (BLAST) algorithm (Altschul et al., 1997). In this work, each cluster was referred as one EST.

The SUCEST data is stored in a MySQL relational database. We used Perl scripts to query this database and to cross-match, for each EST, the BLASTX analysis of the cluster consensus sequence against the nr GenBank database (Release 122.0, Benson et al., 2000), and the library of origin of every read representing that EST. A list of all SUCEST ESTs representing exclusively in the AD1 or HR1 cDNA libraries with BLASTX match e-values below $1 \times 10^{-5}$ was constructed. A list of ESTs with reads from the AD1 and HR1 cDNA libraries, but without reads from any other library, was also generated. For quantitative analysis, all 133 ESTs exclusive of AD1 and HR1 as well as the 90 best represented ESTs present only in the AD1 or HR1 cDNA libraries were functionally organized based on SUCEST categorization (Table III, at http://sucest.lad.ic.
unicamp.br/private/mining-reports/RJ/TableIII). The original 18 functional groups of the SUCEST categorization were consolidated into 9 new groups: Cellular Communication and Signal Transduction, RNA Metabolism and Transcription (including all transcription factors), Plant Growth and Development (including cellular dynamics and storage proteins), Biotic and Abiotic Stress Response, Transport (excluding ESTs related to nitrogen metabolism), Mobile Genetic Elements, Nitrogen Metabolism, Other Metabolisms, and Genes with Unknown Function. The ESTs with no matches were not included in the quantitative analysis. The frequencies of reads in each functional category were calculated by dividing the total number of reads of the ESTs classified in each category by the total number of reads of the 223 ESTs exclusively found in the AD1 and HR1 cDNA libraries that we categorized.

The classification of a given EST as preferentially represented in the AD1 and HR1 cDNA libraries was performed using the values of absolute estimate of mRNA abundance - or the frequency estimates in the cDNA libraries. The number of EST reads (sequenced from the 5' end) corresponding to a given mRNA was divided by the total number of reads (sequenced from the 5 ' end) in a given cDNA library. To be considered as preferentially expressed in the infected libraries, the ESTs needed to be represented (i) at least twice in AD1 or HR1 library and (ii) at a ratio (frequency in the AD1 or HR1 library divided by the frequency in the second best represented library of non-infected tissues) $\geq 2$.

\section{RESULTS AND DISCUSSION}

Data is lacking on the plant molecular events involved in the establishment and maintenance of the association between sugarcane and the endophytic diazotrophs Gluconacetobacter diazotrophicus and Herbaspirillum rubrisubalbicans. In our research we investigated sugarcane gene expression during the association by constructing transcription profiles of two EST sets from the SUCEST database: (i) selected ESTs that encode proteins that could play a role during the association and (ii) all ESTs of the cDNA libraries constructed from sugarcane plants inoculated with the diazotrophic endophytes (AD1 and HR1), also called infected cDNA libraries.

\section{Dataset of selected ESTs}

ESTs encoding proteins that might function in the processes involved in the association with the endophytic diazotrophs were selected for the construction of one EST collection. ESTs belonging to three different plant physiological processes contributed to the dataset: nitrogen metabolism, plant growth and plant-microbe signaling. Early nodulin homologues were also included. This dataset was made up of 1827 ESTs (Table I). 
Table I - Dataset of selected ESTs

\begin{tabular}{|c|c|c|c|}
\hline & & Gene & $\mathrm{N}^{\circ}$ of ESTs \\
\hline Nitrogen & etabolism & & \\
\hline & & AS & 27 \\
\hline & $8 \overline{0}$ & AspAT & 22 \\
\hline & 节 & GDH & 8 \\
\hline & & GOGAT & 6 \\
\hline & & $\mathrm{l}_{\mathrm{GS}}$ & 16 \\
\hline & & NR & 4 \\
\hline & & NT & 25 \\
\hline & & $\mathrm{NiR}$ & 2 \\
\hline & 2 & NiT & 5 \\
\hline & & AAT & 31 \\
\hline & 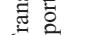 & AT & 24 \\
\hline & & PT & 10 \\
\hline$\frac{\pi}{\sqrt{n}}$ & & $\mathrm{I}(\mathrm{C}) \mathrm{DH}$ & 19 \\
\hline 今. & & |РЕРС & 17 \\
\hline$\pi$ & 施高 & IGlutamate receptor & 1 \\
\hline
\end{tabular}

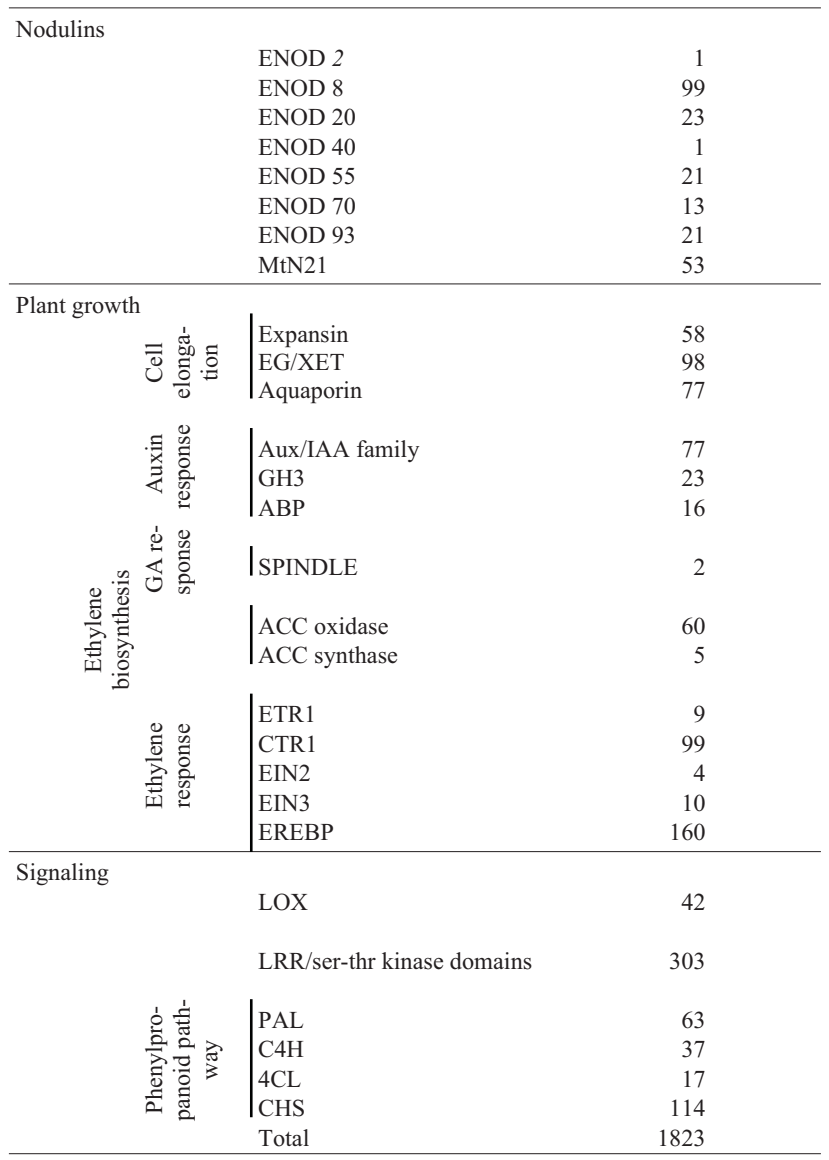

AS - asparagine synthetase, AspAT - aspartate aminotransferase, GS - glutamine synthetase, GDH - glutamate dehydrogenase, GOGAT - glutamate synthase, NR - nitrate reductase, NT - nitrate transporter, NiR - nitrite reductase, NiT - nitrite transporter, AT - ammonium transporter, AAT amino acid transporter, PT - peptide transporter, $\mathrm{I}(\mathrm{C}) \mathrm{DH}$ - isocitrate dehydrogenase, PEPC - phosphoenolpiruravate carboxilase, ACC - 1-aminocyclopropane-1-carboxylic acid, EG- endo-1,4-beta-glucanase, XET xyloglucan endotransglycosylase, ABP- auxin binding protein, IAA- inole-3-acetic acid, ETR1- ethylene-resistent 1, EREBP - ethylene response elements-binding protein, CTR1- constitutive triple response 1, EIN2 ethylene-insensitive 2, EIN3- ethylene-insensitive 3, LRR - leucine-rich repet, PAL - phenylalanine ammonia-lyase, $\mathrm{C} 4 \mathrm{H}$ - cinnamate 4-hydroxilase, 4CL - 4-coumaroyl-CoA ligase, CHS - chalcone synthase, LOX lipoxygenase.
Nitrogen metabolism

An important issue concerning nitrogen-fixing endophytes is whether they contribute fixed-nitrogen to their host. Therefore, nitrogen metabolism was examined in detail in the SUCEST database. The search involved all the enzymes of the amide amino acid metabolic pathway, which is involved in the assimilation of nitrogen into the nitrogen-transporting amino acids glutamine, glutamate, aspartate and asparagine (Lam et al., 1995). The enzymes nitrate reductase and nitrite reductase, implicated in nitrate reduction and uptake, several transporters and the glutamate receptor were also analyzed. For all the proteins investigated we could identify a correlated EST, and all of them were added to the dataset. A large number of ESTs were found for several of the analyzed genes, indicating the presence of many alleles and/or largely represented gene families (Nogueira et al., in preparation). Two enzymes involved in carbohydrate metabolism (phosphoenol pyruvate carboxylase and isocitrate dehydrogenase) were also included in the dataset, as they provide carbon backbone for the nitrogen metabolism pathway.

\section{Plant growth}

Sevilla et al. (2001) have demonstrated that the growth of sugarcane is stimulated by inoculation with endophytic diazotrophs. Plant growth is achieved basically by cell division and cell expansion and plant growth substances are described as upstream coordinators of both cellular events (Davies, 1987). In order to obtain a general view of these processes in sugarcane plantlets inoculated with the diazotrophic endophytes, a group of ESTs related to cell division, cell elongation and the response to plant growth substances were selected (Table I). The dataset of cell cycle controlling genes from sugarcane is described elsewhere (Andrietta et al., in this issue). For the cell expansion analysis, ESTs encoding aquaporins and the cell wall loosening agents (expansins, xyloglucan endotransglycosylase and endo-1,4-B-D-glucanase) (Cosgrove, 2000) were added to the dataset.

ESTs related to three classes of plant growth hormones (auxin, gibberellin and ethylene) were also selected. Endophytic diazotrophs produce the phytohormones indole-3-acetic acid and gibberellin. Therefore, we included in the dataset genes implicated in the response to auxin (the aux/IAA family, GH3 and auxin binding proteins (Guilfoyle, 1999) and gibberellin (SPINDLE (Jacobsen et al., 1998)). Frequently, ethylene responses are associated with auxin responses, probably due to the ability of auxins to promote ethylene synthesis (Taiz and Zeiger, 1998). Also, a role for ethylene in plant-microbe interaction responses has been suggested (Spaink, 1997). Thus, enzymes of the biosynthetic pathway of ethylene (ACC synthase and ACC oxidase) and genes of the ethylene signal transduction path- 
way (ETR1 receptor, CTR1 serine/threonine protein kinase, EIN2, EIN3 transcription factor and ERE-binding proteins) were also added to the EST dataset (Taiz and Zeiger, 1998).

\section{Plant / microbe signaling}

Detailed knowledge of the signaling pathways mediating the interaction between sugarcane and diazotrophic endophytes is lacking. In general, plant-microbe signaling involves an intricate molecular network of metabolite and signal exchange (Baker et al., 1997). Three of these signaling pathways were included in our analysis.

Plant R genes play a key role in the recognition of microbes by plants (Baker et al., 1997). These genes appear to encode receptors and can be classified into five distinct classes that share common structural features such as a leucine-rich repeat (LRR) motif or a serine-threonine kinase domain. We included in our dataset 303 ESTs encoding proteins with LRR and/or ser-thr kinase domains. Flavonoids are secondary products that play important roles in plant-microbe interactions, both as signaling molecules and defense compounds (Sjirley, 1996). ESTs encoding the first three enzymes of the general phenylpropanoid pathway (PAL, C4H, 4CL) and the enzyme chalcone synthase, the first committed enzyme in flavonoid biosynthesis, were also added to the dataset. Finally, ESTs encoding lipoxygenases were also included in the EST set because an increase in lipoxygenase activity, which participates in the peroxidation of membrane lipids and synthesis of signaling molecules, is commonly observed in plant-microbe interactions (Fidantisef, 1999).

\section{Early nodulin homologues}

In order to compare the early events occurring in the sugarcane-endophytes association with those taking place in the establishment of legume-rhizobia symbiosis, we performed an intensive search of ESTs encoding early nodulin homologues. Nodulins are plant proteins specifically synthesized in nodules (Munõz et al., 1996). Usually, they are members of a protein family that play a role in nodule functioning, but are also active in other physiological processes. Some nodulin-homologues were not represented in the SUCEST database, such as ENOD 3, 5, 10, 12, 13 and 14. Nevertheless, ESTs encoding ENOD 2, 8, 20, 40, 55, 70, 93 and MtN21 were identified and added to our EST collection.

EST representation in the AD1 and HR1 cDNA libraries.

In order to examine sugarcane gene expression during the association with the diazotrophic endophytes, we constructed transcriptional profiles of two different EST sets (our selected EST dataset and the complete EST set of the infected cDNA libraries) using two different approaches.

In the first approach, examination of the complete EST set of the infected cDNA libraries, we catalogued all ESTs represented exclusively by reads from the AD1 and HR1 cDNA libraries, or from both libraries simultaneously . From the 30,137 sequenced reads of the AD1 and HR1 cDNA libraries, 2,234 reads (7.4\%) were exclusive for the AD1 library and 1,727 reads (5.7\%) were exclusive from the HR1 library while 354 reads (1.2\%) represented ESTs found in both libraries. All 133 ESTs exclusively represented in both infected cDNA libraries, and the 90 best-represented ESTs exclusive for the AD1 or HR1 cDNA libraries, were classified by putative biological function into nine categories. The generated catalogue is presented in Table III (http://sucest.lad.ic.unicamp.br/private/mining-reports/RJ/TableIII). Figure 1 shows the frequency of reads exclusive to the AD1 and/or HR1 cDNA libraries per functional category. The EST data revealed 33 genes of unknown function exclusively expressed in the infected cDNA libraries ( $25 \%$ of the total reads). In addition, several ESTs belonging to distinct functional categories, e.g. transporters, transcription factors and protein kinases, were

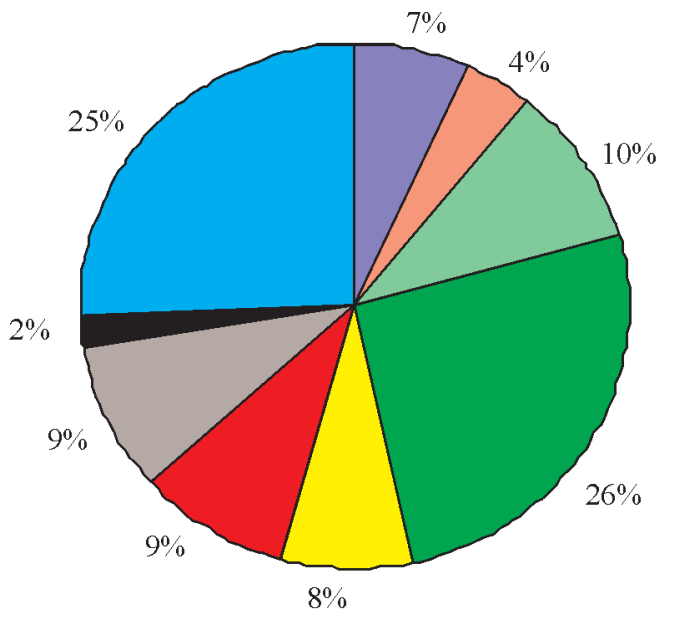

\begin{tabular}{l}
\hline Cellular communication/Signal transduction \\
Nitrogen metabolism \\
RNA metabolism and transcription \\
Other metabolisms \\
Plant growth and development \\
Biotic and abiotic stress response \\
Transport \\
Mobile genetic elements \\
Unkown function
\end{tabular}

Figure 1 - Transcriptional profile of the dataset of ESTs exclusively represented in the AD1 and HR1 cDNA libraries, according to their biological function. The frequency of reads in each functional category was calculated as explained in Material and Methods. The ESTs with no matches were not included in the quantitative analysis. 
identified and are candidates for playing a role in the regulation of the plant-bacteria association.

In the second approach, we calculated the representation in the AD1 and HR1 cDNA libraries of the ESTs from the selected dataset. ESTs with a ratio (frequency in the AD1 or HR1 library divided by the frequency in the second best represented library of non-infected tissues) $\geq 2$ were classified as preferentially expressed in sugarcane plants inoculated with the endophytic diazotrophs (Methods). ESTs only represented in the AD1 and/or HR1 cDNA libraries were classified as exclusive for these libraries. As discussed below, by this analysis, we could identify in the

Table II - ESTs preferentially or exclusively expressed in AD1 and/or HR1 cDNAs libraries.

\begin{tabular}{|c|c|c|c|c|c|c|}
\hline Gene & & EST ID & No. reads & $\% \mathrm{AD} 1$ & $\% \mathrm{HR} 1$ & EST representation \\
\hline \multicolumn{7}{|l|}{ N Metabolism } \\
\hline Nitrate reduction and uptake & NT & 54104 & 4 & 100 & 0 & Exclusive \\
\hline \multirow[t]{3}{*}{ Amide aminoacid biosynthesis } & AS & 76619 & 2 & 0 & 100 & Exclusive \\
\hline & & 100680 & 2 & 0 & 100 & Exclusive \\
\hline & & 50761 & 3 & 100 & 0 & Exclusive \\
\hline Carbohydrate & $\mathrm{I}(\mathrm{C}) \mathrm{DH}$ & 87224 & 4 & 0 & 69 & 2,3 \\
\hline metabolism & PEPC & 58931 & 11 & 39 & 12 & 2,5 \\
\hline \multirow[t]{5}{*}{ Transporters } & PT & 5065 & 2 & 0 & 100 & Exclusive \\
\hline & & 15891 & 6 & 0 & 70 & 3,9 \\
\hline & & 17610 & 5 & 100 & 0 & Exclusive \\
\hline & & 54492 & 4 & 50 & 50 & Exclusive \\
\hline & & 32426 & 2 & 0 & 100 & Exclusive \\
\hline \multicolumn{7}{|l|}{ Plant growth } \\
\hline \multirow[t]{3}{*}{ Cell elongation } & $\beta$-expansin & 12975 & 2 & 100 & 0 & Exclusive \\
\hline & EG & 56529 & 7 & 22 & 34 & 2,0 \\
\hline & Aquaporin & 107056 & 4 & 0 & 100 & Exclusive \\
\hline \multirow[t]{2}{*}{ Cell division } & CKI & 7843 & 2 & 0 & 100 & Exclusive \\
\hline & CYCD3 & 51463 & 2 & 40 & 60 & Exclusive \\
\hline \multirow[t]{4}{*}{ Hormone response } & Aux/IAA & 53759 & 2 & 40 & 60 & Exclusive \\
\hline & EREBP & 64415 & 3 & 100 & 0 & Exclusive \\
\hline & ETR1 & 26767 & 2 & 100 & 0 & Exclusive \\
\hline & EIN2 & 17380 & 4 & 0 & 80 & 4,1 \\
\hline \multicolumn{7}{|l|}{ Nodulins } \\
\hline & ENOD 8 & 55489 & 9 & 15 & 34 & 2,3 \\
\hline & & 82886 & 2 & 40 & 60 & Exclusive \\
\hline & & 52843 & 3 & 100 & 0 & Exclusive \\
\hline & ENOD 70 & 14046 & 5 & 0 & 45 & 2,0 \\
\hline & & 15909 & 4 & 0 & 100 & Exclusive \\
\hline & $\mathrm{MtN} 21$ & 56166 & 7 & 47 & 53 & Exclusive \\
\hline \multicolumn{7}{|l|}{ Signaling } \\
\hline & LRR / & 20124 & 4 & 0 & 100 & Exclusive \\
\hline & ser-thr knase & 32734 & 4 & 75 & 0 & 3,0 \\
\hline & domains & 38078 & 6 & 83 & 0 & 5,0 \\
\hline & & 18395 & 6 & 0 & 69 & 3,9 \\
\hline & & 62654 & 2 & 100 & 0 & Exclusive \\
\hline & LOX & 15644 & 5 & 0 & 80 & 3,9 \\
\hline \multirow[t]{2}{*}{ Phenylpropanoid pathway } & $\mathrm{CHS}$ & 100590 & 4 & 67 & 33 & Exclusive \\
\hline & PAL & 8554 & 2 & 0 & 100 & Exclusive \\
\hline
\end{tabular}

Each EST was identified by its correlated cluster number in the SUCEST database (EST ID). The number of reads of each EST is indicated (No. reads). The frequency of reads of each EST present in AD1 and/or HR1 cDNA libraries (\% AD1 and \% HR1) and the EST representation (frequency in AD1 or HR1 library/frequency in the second best represented library of non-infected tissues) was calculated according to Material and Methods. ESTs represented only in AD1 and/or HR1 cDNA libraries were classified as Exclusive. 
four groups of selected ESTs, those preferentially or exclusively expressed in the AD1 and HR1 cDNA libraries (Table II) (discussed below).

Gene expression related to nitrogen-fixing association in sugarcane

An important question concerning the association of sugarcane plants and diazotrophic endophytes is whether the plant host provides only a niche for bacterial growth or is actively involved in promoting the association. Evidence indicates that the plant is taking part in the process, as the differences in the contribution of BNF to nitrogen balance in the plant are dependent on the sugarcane genotype (Urquiaga et al., 1992).

Performing a computer-based analysis of EST frequencies in the AD1 and HR1 cDNA libraries, we generated an inventory of candidate genes whose expression may possibly be regulated by the nitrogen-fixing association (Table II; and Table III in http://sucest.lad.ic.unicamp.br/ private/mining-reports/RJ/TableIII). No in vitro evidence was obtained to determine whether the predicted changes in gene expression actually reflected mRNA transcript abundance. However, experiments to confirm computer-based EST expression profile data have shown $60-90 \%$ of correlation with RT-PCR and northern blot results (Lee et al., 1995, Hwang et al., 2000).

The data suggest that the plant might be assimilating and metabolizing fixed-nitrogen supplied by the bacteria. Three forms of asparagine synthetase were found exclusively represented in the HR1 and AD1 cDNA libraries. This enzyme catalyses the synthesis of asparagine, a major nitrogen-transporting amino acid in several plant species (Lam et al., 1995). Two classes of transporter (nitrate and peptide) were found exclusively represented in the infected libraries and one form of peptide transporter is preferentially expressed in the HR cDNA library. In addition, homologues of the two enzymes that provide carbon backbone for the amide amino acid pathway (PEPC and $\mathrm{I}(\mathrm{C}) \mathrm{DH})$ were preferentially expressed in the infected libraries. Comparison with the nitrogen metabolism in other nitrogen-fixing associations revealed that nodule-enhanced isoforms of AS and PEPC have been described in several legumes (Vance et al., 1994) and a nodule-specific peptide transporter was reported in Lotus japonicus (Szczyglowski et al., 1997). However, I(C)DH enhanced expression has never been reported in nodules, and Lancien et al. (2000) has suggested that AspAT could be the main enzyme providing 2-oxoglutarate for the rhizobia symbiosis.

Our data also indicate that hormones are probably involved in plant developmental responses during the establishment and/or maintenance of these diazotrophic associations. We found a member of the Aux/IAA family of putative transcription factors exclusively represented in both the AD1 and HR1 cDNA libraries. These proteins are induced only by biologically active auxin, and they participate in auxin signaling (Guilfoyle, 1999). We classified three members of the ethylene response pathway as differentially expressed in the infected cDNA libraries, implying that this hormone might participate in the association. As discussed below, ethylene may be regulating plant developmental processes, but it can also be involved in the plant-bacteria signaling.

Both hormones so far identified as being produced by the bacteria (auxin and gibberellin) are known to promote cell elongation (Davies, 1987). Our data showed an exclusive and a preferential expression of two genes encoding cell wall loosening agents (a beta expansin and a endo-1,4-beta-glucanase, respectively) in the infected cDNA libraries. Interestingly, beta expansins have been demonstrated to be one of the agents involved in cell wall expansion in grasses, in contrast to alpha expansins that are related to wall loosening in both dicotyledons and monocotyledons (Cosgrove, 2000). We also found an aquaporin, a delta-type tonoplast intrinsic protein (TIP), preferentially expressed in the infected libraries. Evidences that delta-type TIP are present during cell elongation were reported in radish and cotton (Higushi et al., 1998). Also, we found that beta tubulin and microtubule-associated protein homologues are exclusively present in both AD1 and HR1 cDNA libraries (Table III), both of these genes having been implicated in cell elongation (Sawano et al., 2000, Munoz et al., 1998). These data suggest that cell expansion might be contributing to plant growth during the sugarcane/diazotrophic endophyte association. However, a role for cell division does not become clear from our analysis. We found two forms of the cell cycle controlling genes (CYCD3 and CKI) exclusively expressed in the infected cDNA libraries. Cyclin D promotes entering into the cell cycle during G1/S transition and the cell cycle inhibitor CKI interacts with $\mathrm{CycD} 3$, blocking cell division (Mironov et al., 1999). In the set of ESTs exclusively expressed in AD1 and HR1 cDNA libraries (Table III), we found ESTs for histone $\mathrm{H} 3$ and histone $\mathrm{H} 4$, genes that are specifically expressed in dividing cells during the S-phase (Meshi et al., 2000). We speculate that cell division is possibly triggered in plants inoculated with the diazotrophic endophytes, and that CKI is just temporally and/or spatially modulating the process.

Despite the apparent beneficial and non-pathogenic aspects of the association, it is reasonable to expect that, to control endophyte colonization and overgrowth, sugarcane might have evolved mechanisms of bacteria recognition, leading to defense responses against the endophytes. We have examined some of these signaling pathways and all of them exhibited ESTs differentially expressed in the AD1 and HR1 cDNA libraries. Although there is no evidence for race-specific $\mathrm{R}$ gene signaling pathways in the sugarcane-diazotrophic endophyte association, we have found ESTs encoding proteins that contain LRR/kinase domains 
exclusively or preferentially expressed in the infected libraries. Also, some protein kinases and phosphatases and one receptor-like kinase are represented in the set of ESTs exclusively expressed in AD1 and HR1 libraries (Table III). These data suggest the participation of receptors and protein kinases in the signal transduction pathways of plant-bacteria response. One lipoxygenase form was classified as preferentially expressed in the HR1 library, suggesting a possible role of oxygenated derivatives of polyunsaturated fatty acids as signal molecules. Forms of enzymes of the phenylpropanoid (PAL) and of the flavonoid (CHS) pathways were exclusively represented in the infected libraries. Isoflavonoid compounds such as phytoalexins can function not only as defense factors inhibiting bacteria growth but also as positive signals in the rhizobia association, acting as chemo-attractants, promoting bacteria growth and inducing nodulation genes (Dakora and Phillips, 1996). In soybean nodules, a particular subset of the PAL and CHS gene families are induced, whereas distinct isoforms are involved in the pathogenic association. Our data suggest that flavonoids could trigger sugarcane responses to endophytic colonization, although we, as yet, cannot associate flavonoids as positive or negative signals for the establishment of endophytes. Ethylene has negative effects on the infection and nodulation processes in various legumes. It plays a role in the rhizobia symbiosis by controlling the position and number of nodules (Spaink, 1997). The presence of members of the ethylene response pathway in the group of ESTs differentially expressed during the association could suggest a role for this hormone in the control of the growth of the endophytes.

Legume nodule-enhanced gene expression was correlated with the sugarcane expression profiles generated, in order to determine probable mechanisms involved in such contrasting nitrogen-fixing associations. Several of the sugarcane genes discussed above, possibly involved in nitrogen metabolism and plant-bacteria signaling during endophytic diazotroph association, also seem to act as nodule-enhanced genes. Specifically, we have investigated early-nodulins homologues in sugarcane. Previous studies have identified homologues of ENOD5 and ENOD40 in the sugarcane genome, using southern analysis (Reddy et al., 1999). We have found early-nodulin ESTs exclusively represented in the infected libraries. enod8 shows similarity to myrosinase-associated protein (MyAP), associated with the plant defense responses (Taipalensu et al., 1996). Both ENOD70 and MtN21 encode membrane proteins, but the function of MtN21 is still unknown. ENOD70 shows homology with a sulfate transporter and has a possible role in nutrient supply during plant-microbe symbiogenesis $(\mathrm{Mu}-$ ñoz et al., 1996).

Genome-based resources are useful tools to investigate large numbers of genes simultaneously and are efficient methods for gene discovery. Our results provided insights into sugarcane genes and processes that might be



Figure 2 - BNF in sugarcane. Hypothetical model for the sugarcane molecular mechanisms involved in the association with endophytic diazotrophs.

examined further in order to understand the basic questions of the plant association with endophytic diazotrophs (Figure 2). In addition, the investigation of the biological function of the unclassified ESTs exclusively expressed in the infected cDNA libraries may lead to the identification of novel genes specifically involved in this association.

\section{RESUMO}

Diversos genótipos brasileiros de cana-de-açúcar são capazes de crescer com baixa adição de adubos nitrogenados, obtendo elevadas contribuições da Fixação Biológica de Nitrogênio (FBN). Um tipo especial de associação com bactérias fixadoras de nitrogênio foi descrito em cana-de-açúcar, onde as bactérias endofíticas, como Gluconacetobacter diazotrophicus e Herbaspirillum spp., colonizam o interior dos tecidos vegetais, sem causar sintomas de doença. Com o objetivo de tentar entender o papel da cana-de-açúcar nesse tipo de associação, nós investigamos os perfis de expressão gênica de plantas colonizadas pelos diazotróficos endofíticos, usando o banco de dados do SUCEST. Um catálogo com os genes de cana-de-açúcar que são candidatos a se expressar exclusivamente ou preferencialmente durante a associação foi gerado. Esses dados preliminares sugerem que a cana-de-açúcar deve ter uma participação ativa na interação, respondendo a diversos processos metabólicos durante a associação.

\section{ACKNOWLEDGMENTS}

We thank FAPESP for giving us the possibility to participate in the SUCEST Genome Project. FAPERJ, FINEP/PRONEX, CNPq and CAPES supported the research.

\section{REFERENCES}

Altschul, S.F., Madden, T.L., Schäffer, A.A., Zhang, J., Zhang, Z., Miller, W., and Lipman, D.J. (1997). Gapped BLAST and PSI-BLAST: a new generation of protein database search programs. Nucleic Acids Res 25 (17): 3389-3402. 
Baker, B., Zambryski, P., Staskawicz, B. and Dinesh-Kumar, S.P. (1997). Signaling in plant-microbe interactions. Science 276: 726-733.

Baldani, J.I., Caruso, L., Baldani, V.L.D., Goi, S.R. and Döbereiner, J. (1997). Recent advances in BNF with non-legume plants. Soil Biology and Biochemistry 29: 911-922.

Bastian, F., Cohen, A., Piccoli, P., Luna, V., Baraldi, R. and Bottini, R. (1998). Production of indole-3-acetic acid and giberellins $\mathrm{A}(1)$ and $\mathrm{A}(3)$ by Gluconacetobacter diazotrophicus and Herbaspirillum seropedicae in chemically-defined culture media. Plant Growth Regul. 24 (1): 7-11.

Benson, D.A., Karsch-Mizrachi, I., Lipman, D.J., Ostell, J., Rapp, B.A., and Wheeler, D.L. (2000). GenBank. Nucleic Acids Res 28 (1): 15-18.

Cosgrove, D.J. (2000). Expansive growth of plant cell walls. Plant Physiol.Biochem. 38: 109-124.

Dakora, F.D. and Phillips, D.A. (1996). Diverse functions of isoflavonoids in legumes transcend anti-microbial definitions of phytoalexins Physiol. Mol. Plant Pathol. 49 (1): $1-20$.

Davies, P.J. (1987). In: Plant hormones and their role in the plant growth and development: their nature, occurrence, and func tions (Davies, P.J., ed.) Dordrechecht, Netherlands, Martinus Nijhoff Publishers.

Fidantsef, A.L., Stout, M.J., Thaler, J.S., Duffey, S.S. and Bostock, R.M. (1999). Signal interactions in pathogen and insect attack: expression of lipoxygenase, proteinase inhibitor II, and pathogenesis-related protein P4 in the tomato, Lycopersicon esculentum Physiol. Mol. Plant Pathol. 54 (3-4): 97-114.

Fuentes-Ramirez, L.E., Jimenez-Salgado, T., Abarca-Ocampo, I.R. and Caballero-Mellado, J. (1993). Gluconacetobacter diazotrophicus, an indolacetic acid-producing bacterium isolated from sugarcane cultivars in Mexico. Plant Soil 154: 145-150.

Guilfoyle, T.J. (1999). Auxin-regulated genes and promoters. In: Biochemistry and molecular biology of plant hormones (Hooykaas, P.J.J., Hall, M.A. and Libbenga, K.R., eds). Elsevier, Amsterdam, pp. 423-459.

Higushi, T., Suga, S., Tsuchyia, T., Hisada, H., Morishima, S., Okada, Y. and Maeshima, M. (1998). Molecular cloning, water channel activity and tissue specific expression of two isoforms of radish vacuolar aquaporin. Plant Cell Physiol. 39: 905-913.

Hwang, D.M., Dempsey, A.A., Lee, C.Y. and Liew, C.C. (2000). Identification of differentially expressed genes in cardiac hypertrophy by analysis of expressed sequence tags. Genomics 66: 1-4.

Jacobsen, S.E., Olszewski, N.E. and Meyerowitz, E.M.(1998). SPINDLY's role in the gibberellin response pathway. Symp. Soc. Exp. Biol. 51: 73-8.

Lam, H.M., Coschigano, K., Schultz, C., Melo-Oliveira, R., Tjaden, G., Oliveira, I., Ngai, N. Hsieh, M.H. and Coruzzi, G. (1995). Use of Arabidopsis mutants and genes to study amine amino acid biosynthesis. Plant Cell 7: 887-898.

Lancien, M., Gadal, P. and Hodges, M. (2000). Enzyme redundancy and the importance of 2-oxoglutarate in higher plant ammonium assimilation. Plant Physiol. 123: 817-824.
Lee, N.H., Weinstock., K.G., Kirkness, E.F., Earle-Hughes, J., Fuldner, R.A., Marmarros, S., Glodek, A., Gocayne, J.D., Adams, M.D., Kerlavage, A.R., Fraser. C.M. and Venter, C. (1995). Comparative expressed-sequence-tag analysis of differential gene expression profiles in PC-12 cells before and after nerve growth factor treatment. Proc. Natl. Acad. Sci. USA 92: 8303-8307.

Mironov, V., De Veylder, L., Van Montagu, M. and Inzé, D. (1999). Cyclin-dependent kinases and cell division in plants - the nexus. Plant Cell 11: 509-521.

Meshi, T., Taoka, K. and Iwabuchi, M. (2000). Regulation of histone gene expression during the cell cycle. Plant Mol. Biol. 43: 643-657.

Muñoz, J.A., Palomares, A.J. and Rated, P. (1996). Plant genes induced in the Rhizobium-legume symbiosis. World Journal of Microbiology \& Biotechnology 12: 189-202.

Munoz, F.J., Labrador, E. and Dopico, B. (1998). Brassinolides promote the expression of a new Cicer arietinum beta-tubulin gene involved in the epicotyl elongation. Plant Mol. Biol. 38 (5): 07-817.

Ohlrogge, J. and Benning, C. (2000). Unraveling plant metabolism by EST analysis. Curr. Opin. Plant Biol. 3: 224-228.

Reddy, P.M., Aggarwal, R.K., Ramos, M.C., Ladha, J.K., Brar, D.S. and Kouchi, H. (1999). Widespread occurrence of the homologues of the early nodulin (ENOD) genes in Oriza species and related grasses. Biochem. Biophys. Res. Commun. 258: 148-154.

Reinhold-Hurek, B. and Hurek, T. (1998). Life in grasses: diazotrophic endophytes. Trends Microbiol. 6(4): 139-144.

Sawano, M., Shimmen, T. and Sonobe, S. (2000). Possible involvement of $65 \mathrm{kDa}$ MAP in elongation growth of adzuki bean epicotyls. Plant Cell Physiol. 41 (8): 968-976.

Sevilla, M., Burris, R.H., Gunapala, N. and Kennedy, C. (2001) Comparison of benefit to sugarcane plant growth an ${ }^{15} \mathrm{~N}_{2}$ incorporation following inoculation of sterile plants with Gluconacetobacter diazotrophicus wild-type and Nif mutant strains. Mol. Plant-Microbe Interact. 14 (3): 358-366.

Shirley, B.W. (1996).Flavonoid biosynthesis:'new'functions for an 'old' pathway. Trends Plant Sci. 1 (11): 377-382.

Spaink, H.P. (1997). Ethylene as a regulator of Rizhobium infection. Trends in Plant Science 2 (6): 203-204.

Szczyglowski, K., Hamburger, D., Kapranov, P. and de Bruijn, F.J. (1997). Construction of a Lotus japonicus late nodulin expressed sequence tag library and identification of novel nodule-specific genes. Plant Physiol. 114 (4): 1335-46.

Taipalensuu J., Falk A., and Rask L.(1996). A wound and methyl jasmonate-inducible transcript coding for a myrosinase-associated protein with similarities to an early nodulin. Plant Physiol. 110 (2): 483-91.

Taiz, L. and Zeiger, E. (1998). Ethylene. In: Plant Physiology (Brady, E.B., Donohoe, L., Funston, J. and Mills, C., eds.). Sinauer Associates, Sunderland, pp. 651-670.

Urquiaga, S., Cruz, H.S. and Boddey, R.M. (1992). Contribution of nitrogen fixation to sugarcane: nitrogen-15 and nitrogen balance estimates. Soil Sc. Soc. Am. J. 56: 105-114.

Vance, C.P., Gregerson, R.G., Robinson, D.L., Miller, S.S. and Gantt, J.S. (1994). Primary assimilation of nitrogen in alfalfa nodules: molecular features of the enzymes involved. Plant Sci. 101: 51-64. 